\title{
Modeling of the Aeration System of a Sequencing Batch Reactor
}

\author{
Jacek Zaburko', Radosław Głowienka', Marcin K. Widomski", \\ Joanna Szulżyk-Cieplak², Roman Babko³, Grzegorz Łagód' \\ 1 Lublin University of Technology, Faculty of Environmental Engineering, Nadbystrzycka 40B, 20-618 Lublin, \\ Poland \\ 2 Lublin University of Technology, Faculty of Fundamentals of Technology, Nadbystrzycka 38, 20-618 Lublin, \\ Poland \\ ${ }^{3}$ Schmalhausen Institute of Zoology National Academy of Sciences of Ukraine, B. Khmelnitsky 15, 01030 Kyiv, \\ Ukraine \\ * Corresponding author's e-mail: m.widomski@pollub.pl
}

\begin{abstract}
The use of modern methods as well as modeling and simulation tools in the design of bioreactors allows for the analysis of the flow phenomena in a short period of time without the need of physical model preparation, and thus for the optimization of existing solutions. The article presents the simulations of the aeration process in an SBRtype bioreactor, realized by means of computational fluid dynamics (CFD) and ANSYS 12.1 software. The subject of the analysis was a diffuser of own design. The Design Modeler 12.1 module was used for the preparation of geometry representing the analyzed design, and the discretization of the continuous domain was carried out with the ANSYS Meshing 12.1 tool. The ANSYS Fluent 6.3 solver was used For model calculations. On the basis of the results obtained from the conducted simulations, it is possible to predict the parameters which will increase efficiency and effectiveness without the need to build a real set of prototype models of aeration systems. The results obtained indicate that an increase in the aeration velocity results in a decrease in the minimum Y-axis velocity for both the mixture and air. The observed differences are caused by the shape of the geometric model and the velocity of the air outlet through the openings, which affects the hydraulic process in the chamber. These processes affect both the amount of oxygen dissolved in the bioreactor and the behavior of the suspension in volume. The turbulence intensity during the aeration process is concerned mainly in the range from 3.9 to $8.7 \%$ and is comparable with the average values of turbulence degree obtained by other researchers. The air bubble diameter ranged from 0.3 to $4.5 \mathrm{~mm}$, in the case of aeration velocity $5.68 \mathrm{~cm} / \mathrm{s}$, a significant part of the chamber were air bubbles with a diameter of 2.6 to $3.9 \mathrm{~mm}$, i.e. they were not the limit values.
\end{abstract}

Keywords: modeling of aeration, CFD simulations, SBR

\section{INTRODUCTION}

Computer modeling can be used in the design of the aeration systems utilized in activated sludge bioreactors [Vanhooren, et al. 2003, Pittoors et al., 2014, Sytek-Szmeichel et al., 2016, Hreiz et al., 2019]. A biological reactor working in a batch system (SBR - sequencing batch reactor) is one of the ways to use the activated sludge technology [Singh et al., 2011, Babko et al., 2017]. The processes occurring during the wastewater treatment take place sequentially in one tank and consist of several successive cycles usually lasting from several to more than ten hours. The work of the bioreactor is a cyclical process in which successive phases such as filling, mixing, aeration, sedimentation and decantation are distinguished. The activated sludge organisms that convert the organic and biogenic compounds into own biomass, gaseous products and water play a key role during the biological decomposition of the pollutants contained in wastewater [Hartman, 1996, Babko et al., 2014, Cydzik-Kwiatkowska et al., 2016]. In order to ensure the right working conditions 
for the organisms, the necessary component supplied during the aeration phase must be the right amount of oxygen for the proper conduct of biochemical processes [Traoré et al., 2005, Sobotka et al., 2015, Tang et al., 2019]. According to the literature, the average demand for activated sludge for oxygen is $2 \mathrm{mg} \mathrm{O}_{2} / 1$ to ensure proper conditions for the nitrification process [Drewnowski, 2019, Zhang et al., 2019]. Aeration time depends on the composition of the wastewater, the condition of the activated sludge and the required treatment efficiency. [Yahi et al., 2014, Habermacher et al., 2015] Good effects are obtained by using alternating aeration so that unit processes can take place under changing oxygen conditions [Witkowska, 2006, Makowska et al., 2009, Bernat et al., 2013, Zhang et al., 2017, Łagód, et al., 2019]; hence, the aeration phase was recognized as the most important part of the bioreactor work cycle [Drewnowski et al., 2019]. The effectiveness of the aeration process largely depends on the use of an appropriate oxygen supply system to the bioreactor, which includes blowers, pipelines, throttles and diffusers [Drewnowski et al., 2018, Drewnowski et al., 2019, Rosso et al., 2008, Wagner et al., 2002, Piotrowski et al., 2019]. The optimal choice is, therefore, an aeration system with low energy consumption and high efficiency [Leu et al., 2009, Lagód et al., 2019, Drewnowski et al., 2019]. Owing to the use of computer simulations, in a short time it is possible to obtain the knowledge of the mechanisms and hydraulic processes occurring in the bioreactor chamber, taking into account the way aeration systems work based on real data under various operating conditions, and enables accurate analyses regarding fluid flow or energy exchange [Fayolle et al., 2007, Karpińska et al., 2017]. Modelling CFD (computational fluid dynamics) allows predicting which changes in a given project will increase the performance without having to modify or install physical systems. The numerical methods and systems on which CFD modeling is based are constantly improved, which is why the simulation results are becoming more and more reliable. The use of the numerical method of fluid mechanics also allows optimizing the designed structure, and thus generate the material and energy savings, leading to the reduction of the negative environmental impact of various devices and machines, improvement of their safety and performance as well as shortening the time of preparing a new structure [Małecka et al., 2011, Yang et al., 2011, Alizadeh et al., 2018]. From an economic point of view, it is reasonable to use computer simulations, because it allows designing and pre-testing a new structure by calculation, eliminating the need to build many prototypes of the modelled device. The results obtained at the stage of simulations allow for the preparation of a pre-verified set of construction solutions, reducing the time necessary to carry out more under in real conditions or on laboratory scale devices to the minimum.

This article presents modeling of the aeration device - diffuser - and the process in the labscale sequencing batch reactor (SBR) implemented with the help of computational fluid dynamics (CFD) and ANSYS FLUENT software.

\section{MATERIALS AND METHODS}

The subject of the research is an inverted Tshaped diffuser with $1 \mathrm{~mm}$ diameter holes characterized by $1 \%$ turbulence intensity generated in the form of a geometric model that has been discretized in a preprocessor. The model crosssections are presented in Figure 1.

The following physicochemical properties of liquids and air at $20^{\circ} \mathrm{C}$ were introduced to the FLUENT Database program: water density $-998.2 \mathrm{~kg} / \mathrm{m}^{3}$, air density $-1.225 \mathrm{~kg} / \mathrm{m}^{3}$, water viscosity $-0.001003 \mathrm{~kg} /(\mathrm{m} \cdot \mathrm{s})$, air viscosity $-1.7894 \cdot 10^{-5} \mathrm{~kg} /(\mathrm{m} \cdot \mathrm{s})$, surface tension $-0.0725 \mathrm{~N} / \mathrm{m}$.

The simulations were carried out for four air outlet velocities from the diffuser openings and for two cross-sections of the geometric model. The air outlet velocities were $3 \mathrm{~cm} / \mathrm{s}, 5.68 \mathrm{~cm} / \mathrm{s}$, $9 \mathrm{~cm} / \mathrm{s}$ and $12 \mathrm{~cm} / \mathrm{s}$. While conducting the simulations, the following parameters were focused upon:

- average velocity values (for mixture, water, air),

- velocity values in the direction of the $\mathrm{Y}$ axis (for mixture and air),

- turbulence intensity (for the mixture),

- diameter of air bubbles.

The research was based on the Realizable K-Epsilon turbulence model for a two-dimensional object using a double precision solver (due to two phases: water and air). This model predicts the behavior and performance of flat and round outflows, and provides better flow simulation results, taking into account boundary layer rotation 


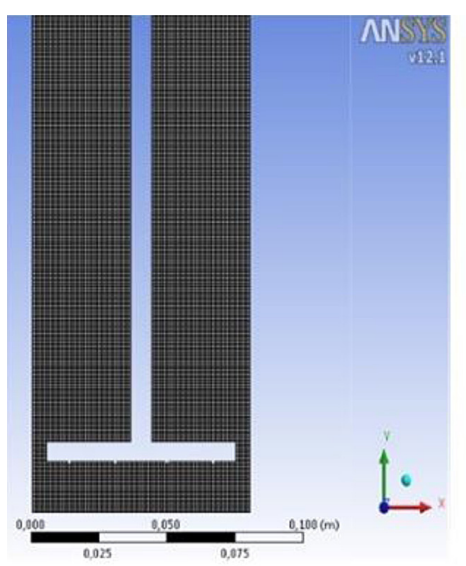

(a)

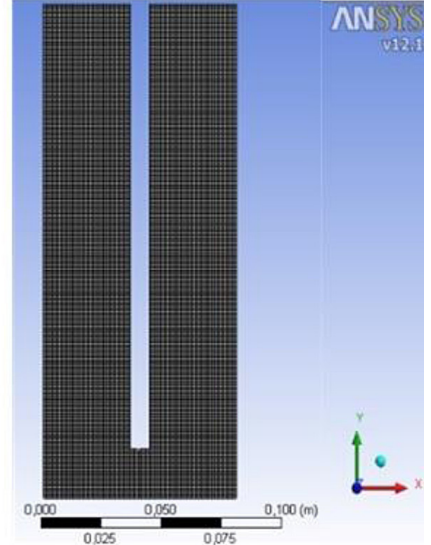

(b)

Figure 1. Model cross-sections $(\mathrm{a}, \mathrm{b})$ made with the DESIGN MODELER tool

under severely adverse pressure gradients, separation and circulation [Zhang et al., 2019].

The transport equations for kinetic energy of turbulence $-k$ and dissipation and energy $-\varepsilon$ take the form of [Cable, 2009]:

$k$ turbulent kinetic energy

$$
\begin{gathered}
\frac{\partial}{\partial t}(\rho k)+\frac{\partial}{\partial x_{j}}\left(\rho k u_{j}\right)=\frac{\partial}{\partial x_{j}}\left[\left(\mu+\frac{\mu_{t}}{\sigma_{k}}\right) \frac{\partial k}{\partial x_{j}}\right]+ \\
+G_{k}+G_{b}-\rho \varepsilon-Y_{M}+S_{k}
\end{gathered}
$$

$\varepsilon$ dissipation

$$
\begin{aligned}
& \frac{\partial}{\partial t}(\rho \varepsilon)+\frac{\partial}{\partial x_{j}}\left(\rho \varepsilon u_{j}\right)=\frac{\partial}{\partial x_{j}}\left[\left(\mu+\frac{\mu_{t}}{\sigma_{\varepsilon}}\right) \frac{\partial \varepsilon}{\partial x_{j}}\right]+ \\
& +\rho C_{1} S \varepsilon-\rho C_{2} \frac{\varepsilon^{2}}{k+\sqrt{v \varepsilon}}+C_{1 \varepsilon} \frac{\varepsilon}{k} C_{3 \varepsilon} G_{b}+S_{\varepsilon}
\end{aligned}
$$

where:

$C_{1}=\max \left[0.43, \frac{\eta}{\eta+5}, \eta=S \frac{k}{\varepsilon}, S=\sqrt{2 S_{i j} S_{i j}}\right.$

where: $G_{k}$ - kinetic energy of turbulence caused by average velocity gradients,

$G_{b}-$ kinetic energy of turbulence due to displacement,

$Y_{M}$-impact of the turbulence fluctuations on the dissipation,

$C_{2}$ and $C_{1 e}-$ constant,

$S_{k}$ and $s_{e}-$ Prandtl numbers for $k$ and $\varepsilon$,

$S_{k}$ and $S_{e}$ - user-defined source conditions.

In the Realizable $k-\varepsilon$ model, the $C_{\mu}$ value is not constant and is determined from the relationship:

$$
C_{\mu}=\frac{1}{A_{0}+A_{s} \frac{k U^{*}}{\varepsilon}}
$$

The values of the model constants are as follows:

$$
C_{1 \varepsilon}=1.44, C_{2}=1.9, \sigma_{k}=1.0, \sigma_{\varepsilon}=1.2 .
$$

\section{RESULTS AND DISCUSSION}

Tables 1 and 2 summarize the results obtained after the simulation in the FLUENT module. On the basis of Tables 1 and 2, an overall increase in the average mixture and water velocity, velocity on the $\mathrm{Y}$ axis for the mixture, and mixture turbulence intensity with an increase in the outlet velocity of air from the diffuser openings can be seen. The differences between the average velocity of the mixture and the water are very small - they appear only in the thousandth part. The velocities of $5.68 \mathrm{~cm} / \mathrm{s}$ and $12 \mathrm{~cm} / \mathrm{s}$ for two crosssections were assumed for the discussion of simulation results.

A graphical visualization of the aeration process for the velocity of $5.68 \mathrm{~cm} / \mathrm{s}$ and for two cross-sections of the geometric model is shown in Figure 2.

On the basis of Figure 2a, it can be concluded that the transverse profile of the average velocity varies considerably. The velocity is from 0 to $10.1 \mathrm{~cm} / \mathrm{s}$. At the bottom of the chamber and near the diffuser's tee, the velocity equals $0 \mathrm{~cm} / \mathrm{sec}$, which indicates the presence of congestion zones. The congestion zones can be eliminated by lowering the position of the diffuser, introducing its rotary motion or changing its shape. The highest velocity of $10.1 \mathrm{~cm} / \mathrm{s}$ is observed near the side surface of the chamber. Due to the glass of which the vessel is made, there is no decrease in velocity near the wall due to dynamic friction and 
Table 1. List of simulation results for the section (a)

\begin{tabular}{|c|c|c|c|c|c|c|c|c|c|}
\hline \multirow{3}{*}{ Parameter } & & \multicolumn{8}{|c|}{ Speed } \\
\hline & & \multicolumn{2}{|c|}{$3[\mathrm{~cm} / \mathrm{s}]$} & \multicolumn{2}{|c|}{$5.68[\mathrm{~cm} / \mathrm{s}]$} & \multicolumn{2}{|c|}{$9[\mathrm{~cm} / \mathrm{s}]$} & \multicolumn{2}{|c|}{$12[\mathrm{~cm} / \mathrm{s}]$} \\
\hline & & $\min$ & $\max$ & $\min$ & $\max$ & $\min$ & $\max$ & $\min$ & $\max$ \\
\hline \multirow{3}{*}{ Average speed $[\mathrm{cm} / \mathrm{s}]$} & mixture & 0 & 6.27906 & 0 & 10.06000 & 0 & 13.21625 & 0 & 14.62435 \\
\hline & water & 0 & 6.27841 & 0 & 10.05918 & 0 & 13.21487 & 0 & 14.62258 \\
\hline & air & 0 & 98.55818 & 0 & 49.84223 & 0 & 68.54171 & 0 & 50.89521 \\
\hline \multirow{2}{*}{$\begin{array}{l}\text { Velocity on the } \mathrm{Y} \text { axis } \\
{[\mathrm{cm} / \mathrm{s}]}\end{array}$} & mixture & -2.84146 & 6.27905 & -4.44023 & 10.05998 & -5.54575 & 13.62122 & -6.18777 & 14.62431 \\
\hline & air & -1.37476 & 98.55818 & -2.06397 & 49.84195 & -2.663 & 68.46771 & -3.16327 & 50.89521 \\
\hline $\begin{array}{l}\text { Turbulence intensity } \\
{[\%]}\end{array}$ & mixture & 0.038 & 3.947 & 0.049 & 6.187 & 0.058 & 7.799 & 0.063 & 8.761 \\
\hline $\begin{array}{l}\text { Diameter of air bubbles } \\
\text { [cm] }\end{array}$ & air & 0.03 & 0.45 & 0.03 & 0.45 & 0.03 & 0.45 & 0.03 & 0.45 \\
\hline
\end{tabular}

Table 2. List of simulation results for the section (b)

\begin{tabular}{|l|c|c|c|c|c|c|c|c|c|}
\hline \multirow{2}{*}{ Parameter } & \multicolumn{9}{c|}{ Speed } \\
\cline { 3 - 10 } & & \multicolumn{2}{|c|}{$3[\mathrm{~cm} / \mathrm{s}]$} & \multicolumn{2}{c|}{$5.68[\mathrm{~cm} / \mathrm{s}]$} & \multicolumn{2}{c|}{$9[\mathrm{~cm} / \mathrm{s}]$} & \multicolumn{2}{c|}{$12[\mathrm{~cm} / \mathrm{s}]$} \\
\cline { 3 - 11 } & $\min$ & $\max$ & $\min$ & $\max$ & $\min$ & $\max$ & $\min$ & $\max$ \\
\hline \multirow{2}{*}{$\begin{array}{l}\text { Average speed } \\
{[\mathrm{cm} / \mathrm{s}]}\end{array}$} & mixture & 0 & 8.63801 & 0 & 12.65870 & 0 & 17.88951 & 0 & 20.22952 \\
\cline { 2 - 11 } & water & 0 & 8.63726 & 0 & 12.65739 & 0 & 17.88705 & 0 & 20.22688 \\
\cline { 2 - 11 } & air & 0 & 63.94366 & 0 & 48.98336 & 0 & 47.47299 & 0 & 55.99093 \\
\hline $\begin{array}{l}\text { Velocity on the Y } \\
\text { axis [cm/s] }\end{array}$ & mixture & -3.12870 & 8.63801 & -4.33725 & 12.65870 & -3.60143 & 17.88950 & -5.47783 & 20.22947 \\
\cline { 2 - 11 } & air & -3.12870 & 63.94362 & -4.33725 & 48.98336 & -3.60143 & -47.4725 & -3.79056 & 55.99083 \\
\hline $\begin{array}{l}\text { Turbulence intensity } \\
{[\%]}\end{array}$ & mixture & 0.019 & 5.987 & 0.025 & 8.073 & 0.009 & 6.360 & 0.051 & 59.368 \\
\hline $\begin{array}{l}\text { Diameter of air } \\
\text { bubbles [cm] }\end{array}$ & air & 0.04 & 0.45 & 0.03 & 0.45 & 0.03 & 0.45 & 0.03 & 0.45 \\
\hline
\end{tabular}

roughness of the material. The chamber volume is dominated by the average velocity in the range from 1 to $5 \mathrm{~cm} / \mathrm{sec}$. Figyre $2 \mathrm{~b}$ shows a higher maximum velocity, which is $12.7 \mathrm{~cm} / \mathrm{sec}$. The maximum velocity occurs near the diffuser and not the side surface of the chamber. In the case of the cross-section no. 2, the area of congestion zones is larger in comparison with the cross-section no.
1. The average velocity in the range from 0.6 to $3.8 \mathrm{~cm} / \mathrm{s}$ prevails in the chamber volume.

An analysis was conducted, related to the relationship between the velocity value at which air is introduced through the diffuser into the reactor chamber, and the average velocity (for the mixture and air) and velocity in the direction of the $\mathrm{Y}$ axis (for the mixture and air) and the turbulence

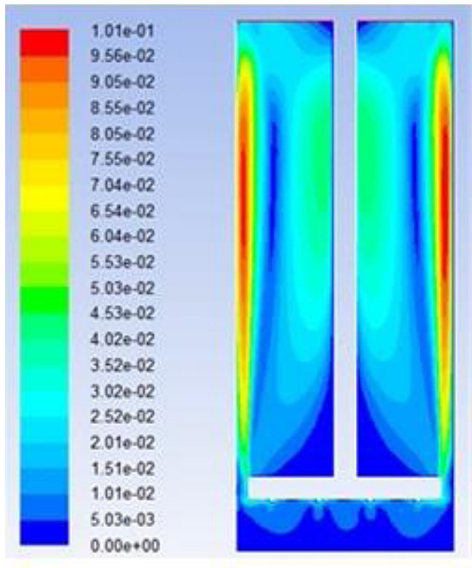

(a)

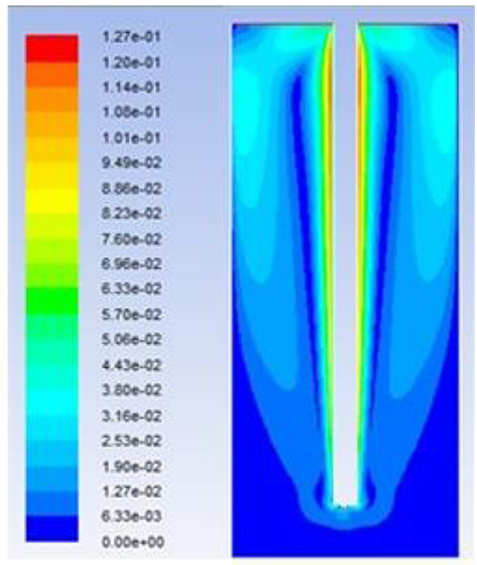

(b)

Figure 2. Distribution of average mixture velocity $[\mathrm{m} / \mathrm{s}]$ for an outlet velocity of $5.68 \mathrm{~cm} / \mathrm{s}$ - cross-sections (a) and (b) 
intensity (for the mixture). In Figures 3-5, both sections were compared in terms of the parameters observed.

On the basis of Figures 3a, 4a and 5, it can be stated that the average velocity, velocity on the $\mathrm{Y}$ axis and turbulence intensity for the mixture are higher in the case of the simulation carried out for the cross-section (a). The mean velocity and velocity on the $\mathrm{Y}$ axis for air (Figures $3 \mathrm{~b}$ and $4 \mathrm{~b}$ ) are higher for the simulation carried out for the cross-section (a) at the aeration velocities of 3 and $9 \mathrm{~cm} / \mathrm{s}$. It was observed that the maximum values of average velocity, velocity on the $\mathrm{Y}$ axis and the turbulence intensity of the mixture increase along with the aeration value. As the aeration increases, the average velocity and the velocity on the Y-axis for air decrease. As the aeration value increases, the minimum velocity values on the $Y$ axis for the mixture and air also decrease. For the aeration velocities of $5.68 \mathrm{~cm} / \mathrm{s}$ and $12 \mathrm{~cm} / \mathrm{s}$, the results are similar. These results are caused by the shape of the geometric model and the velocity of the air outlet through the holes, determining the hydraulic process in the chamber.

The average velocities obtained during modeling in the range of 6-99 $\mathrm{cm} / \mathrm{s}$ are comparable with the literature data [Fayolle et al., 2007, Suchecki et al., 2003]. As far as turbulence intensity during the aeration process is concerned, the results obtained (omitting the result obtained for the air outlet velocity through the diffuser openings of $12 \mathrm{~cm} / \mathrm{s}$ for section no. 2) are in the range from 3.9 to $8.7 \%$ and are also comparable with the average values of turbulence degree obtained by other researchers [Talaga et al., 2008], which are from 5 to $7 \%$.

As a result of the simulations carried out, the air bubble diameter range was 0.3 to $4.5 \mathrm{~mm}$. The same scope was obtained in the article [Kerdouss et al., 2006]. In the case of the aeration velocity of $5.68 \mathrm{~cm} / \mathrm{s}$, a significant part of the chamber were air bubbles with a diameter of 2.6 to $3.9 \mathrm{~mm}$, i.e.

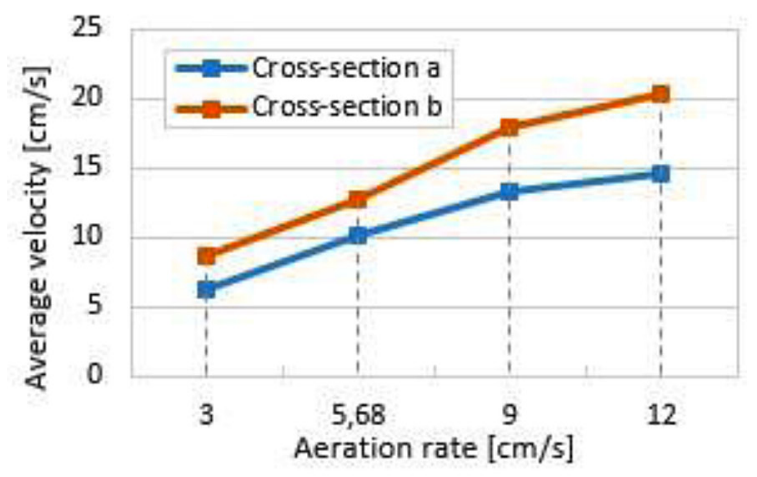

(a)

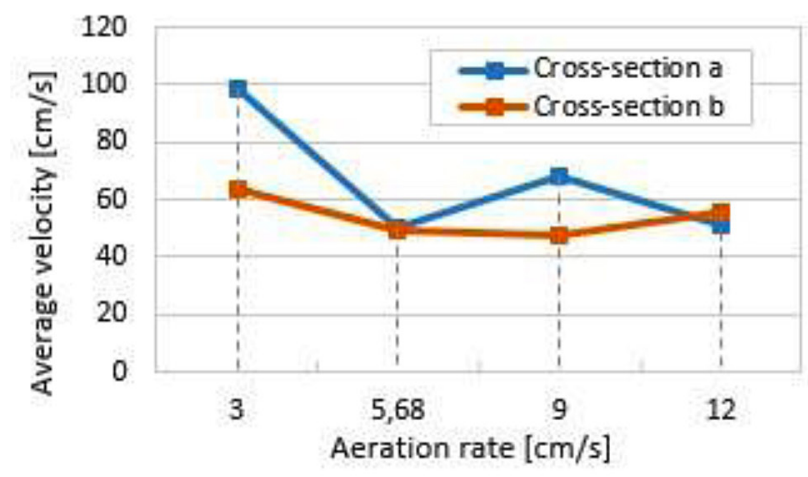

(b)

Figure 3. Average velocity of the mixture (a) and the air (b)

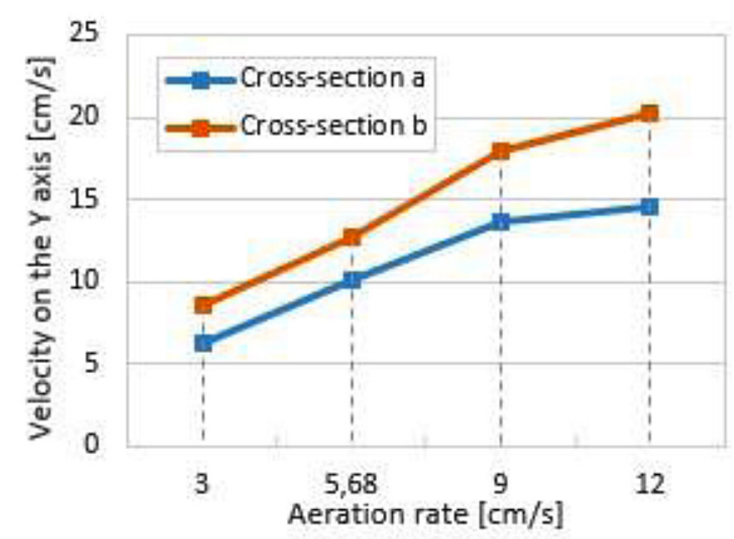

(a)

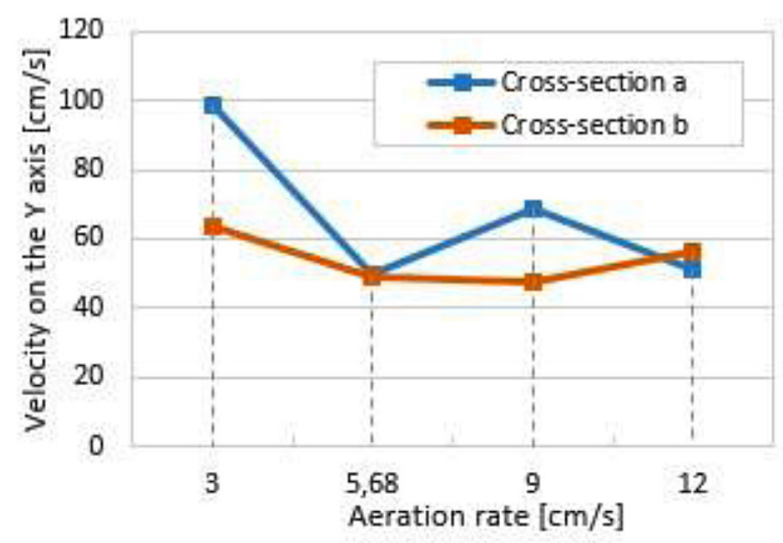

(b)

Figure 4. Velocity values on the $\mathrm{Y}$ axis for the mixture (a) and the air(b) 


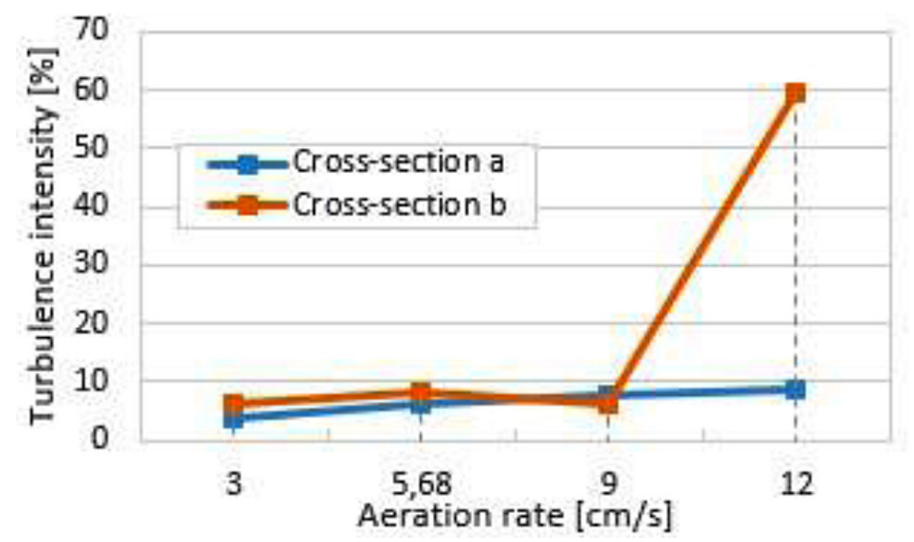

Figure 5. Turbulence intensity of the mixture

they were not limit values. A similar situation occurred at work [Sungkorn et al., 2012]. The air bubbles with a diameter of 3 to $5 \mathrm{~mm}$ occupied a significant part of the tank.

\section{CONCLUSIONS}

The article presents the results of computer modeling of the hydraulic process taking place inside a laboratory SBR-type reactor. For the purpose of the simulation, two sections of the diffuser and the reactor chamber were developed. The simulations were carried out for four values of aeration velocity. The analysis of the obtained test results allowed formulating the following final conclusions:

- The results of the simulation proved that the aeration velocity in sequencing batch reactor can be evaluated by means of CFD modeling and thus describe this important element of the wastewater treatment process.

- The maximum values of the average velocity, the velocity on the $\mathrm{Y}$ axis and turbulence intensity for the mixture increase proportionally to the increase of the aeration values, while the average velocity and the velocity on the $\mathrm{Y}$ axis for air decrease.

- An increase in the aeration velocity results in a decrease in the minimum Y-axis velocity for both the mixture and air. The results are similar for the aeration velocity of 5.68 and $12 \mathrm{~cm} / \mathrm{s}$.

- The observed differences are caused by the shape of the geometric model and the velocity of the air outlet through the openings, which affects the hydraulic process in the chamber. These processes affect both the amount of oxygen dissolved in the bioreactor and the behavior of the suspension in volume.

- The congestion zones located at the bottom of the chamber and near the diffuser tee can be eliminated by lowering the position of the diffuser, introducing its rotary motion or changing its shape.

- The turbulence intensity during the aeration process is concerned (omitting the result obtained for the air outlet velocity through the diffuser openings of $12 \mathrm{~cm} / \mathrm{s}$ for section no. 2) are in the range from 3.9 to $8.7 \%$ and are comparable with the average values of turbulence degree obtained by other researchers.

- The air bubble diameter range was from 0.3 to $4.5 \mathrm{~mm}$. In the case of aeration velocity of $5.68 \mathrm{~cm} / \mathrm{s}$, a significant part of the chamber were air bubbles with a diameter of 2.6 to $3.9 \mathrm{~mm}$, i.e. they were not limit values.

\section{REFERENCES}

1. Alizadeh M., Sadrameli S.M. 2018. Numerical modeling and optimization of thermal comfort in building: Central composite design and CFD simulation. Energ. Build. 164, 187-202.

2. Babko R., Kuzmina T., Jaromin-Gleń K., Bieganowski A. 2014. Bioindication assessment of activated sludge adaptation in lab-scale experiment. Ecol Chem Eng. ser. S, 21(4), 605-616.

3. Babko R., Jaromin-Gleń K., Łagód G., Danko, Y., Kuzmina T., Pawłowska M., Pawłowski A. 2017. Short-term Influence of Two Types of Drilling Fluids on Wastewater Treatment Rate and Eukaryotic Organisms of Activated Sludge in Sequencing Batch Reactors. J. Environ. Qual., 46, 714.

4. Bernat K., Kulikowska D., Zielińska M., CydzikKwiatkowska A., Wojnowska-Baryła I. 2013. 
Simultaneous Nitrification and Denitrification in an SBR with a Modified Cycle During Reject Water Treatmen. Arch. Environ. Prot. 39(1), 83-91.

5. Cable M. 2009. An Evaluation of Turbulence Models for the Numerical Study of Forced and Natural Convective Flow in Atria, Queen's University Kingston, Ontario, Canada.

6. Cydzik-Kwiatkowska A., Zielińska, M. 2016. Bacterial communities in full-scale wastewater treatment systems. Word J. Microb. Biot. 32(4), 1-8.

7. Drewnowski J. 2019. Advanced Supervisory Control System Implemented at Full-Scale WWTP-A Case Study of Optimization and Energy Balance Improvement. Water, 11, 1218

8. Drewnowski J., Remiszewska-Skwarek A., Duda S., Łagód G. 2019. Aeration Process in Bioreactors as the Main Energy Consumer in a Wastewater Treatment Plant. Review of Solutions and Methods of Process Optimization. Processes, 7, 311.

9. Drewnowski J., Remiszewska-Skwarek A., Fernandez-Morales F.J. 2018. Model based evaluation of plant improvement at a large wastewater treatment plant (WWTP). J. Environ. Sci. Health A, 53, 669-675.

10. Fayolle Y., Cockx A., Gillot S., Roustan M., Héduit A. 2007. Oxygen transfer prediction in aeration tanks using CFD. Chemical Engineering Science, 62(24), 7163-7171.

11. Habermacher J., Benetti A.D., Derlon N., Morgenroth E. 2015. The effect of different aeration conditions in activated sludge--Side-stream system on sludge production, sludge degradation rates, active biomass and extracellular polymeric substances. Water Res. 15(85), 46-56.

12. Hartmann L. 1996. Biological wastewater treatment (In Polish), Wyd. Instalator Polski, Warszawa.

13. Hreiz R., Potier O., Wicks J., Commenge J.-M. 2019. CFD Investigation of the effects of bubble aerator layouts on hydrodynamics of an activated sludge channel reactor. Environmental Technology, 40(20), 2657-2670.

14. Karpińska A.M., Bridgeman J. 2017. Towards a robust CFD model for aeration tanks for sewage treatment - a lab-scale study, Engineering Applications of Computational Fluid Mechanics, 11(1), 371-395.

15. Kerdouss F., Bannari A., Proulx P. 2006. CFD modeling of gas dispersion and bubble size in a double turbine stirred tank, Chemical Engineering Science 61, 3313-3322.

16. Łagód G., Piotrowicz A., Gleń P., Drewnowski J., Sabba F. 2019. Modelling of sequencing batch reactor operating at various aeration modes. MATEC Web Conf., 252, 05013.

17. Leu S.Y., Rosso D., Larson L.E., Stenstrom M.K. 2009. Real-time aeration efficiency monitoring in the activated sludge process and methods to reduce energy consumption and operating costs. Water Environ Res. 81(12), 2471-81.

18. Makowska M., Spychała M., Błażejewski R. 2009. Treatment of Septic Tank Effluent in Moving Bed Biological Reactors with Intermittent Aeration. Pol. J. Environ. Stud. 18(6), 1051-1057.

19. Małecka I. 2011. Application of CFD calculations to select capacity of hot water temperature stabilizer in thermal centres (in Polish). Zeszyty Naukowe. Inżynieria Lądowa i Wodna w Kształtowaniu Środowiska, 4, 88-95.

20. Piotrowski R., Paul A., Lewandowski M. 2019. Improving SBR Performance Alongside with Cost Reduction Through Optimizing Biological Processes and Dissolved Oxygen Concentration Trajectory Appl. Sci., 9, 2268.

21. Pittoors E., Guo Y., Van Hulle S.W.H. 2014. Modeling dissolved oxygen concentration for optimizing aeration systems and reducing oxygen consumption in activated sludge processes: a review. Chemical Engineering Communications, 201(8), 983-1002.

22. Rosso D. Stenstrom M.K., Larson L.E. 2008. Aeration of large-scale municipal wastewater treatment plants: state of the art. Water Sci Technol. 57(7), 973-978.

23. Singh M., Srivastava R.K. 2011. Sequencing batch reactor technology for biological wastewater treatment: A review. Asia-Pac J. Chem. Eng. 6(1), 3-13.

24. Sobotka D., Czerwionka K., Makinia J. 2015. The effects of different aeration modes on ammonia removal from sludge digester liquors in the nitritation-anammox proces. Water Sci. Technol. 71(7), 986-995.

25. Suchecki W., Alabrudziński S. 2003. Analysis of the velocity field regarding large elements in the flow (in Polish), Inżynieria i Aparatura Chemiczna, 5, 6-13.

26. Sungkorn R., Derksen J.J., Khinast J.G. 2012. Modeling of aerated stirred tanks with shear-thinning power law liquids, International Journal of Heat and Fluid Flow 36, 153-166.

27. Sytek-Szmeichel K., Podedworna J., ZubrowskaSudol M. 2016. Efficiency of Wastewater Treatment in SBR and IFAS-MBSBBR Systems in Specified Technological Conditions. Water Sci Technol ,73, 1349-1356.

28. Talaga J., Wójtowicz R., Duda A. 2008. Investigations of turbulence intensity in stirred vessels with two impellers (in Polish), Czasopismo Techniczne. Mechanika, 105(2-M), 361-370.

29. Tang M., Liu J. 2019. Aeration Optimization of Large-Scale Membrane Bioreactors in a Sewage Treatment Plant. Water Practice And Technology, 14,198-202. 
30. Traoré A., Grieu S., Puig S., Corominas L., Thiery F., Polit M., Colprim J. 2005. Fuzzy Control of Dissolved Oxygen in a Sequencing Batch Reactor Pilot Plant. Chem Eng J, 1, 13-19

31. Vanhooren H., Meirlaen J., Amerlinck Y., Claeys F., Vangheluwe H., Vanrolleghem P.A. 2003. WEST: Modelling biological wastewater treatment. J. Hydroinform. 5(1), 27-50.

32. Wagner M, Cornel P, Krause S. 2002. Efficiency of different aeration systems in full scale membrane bioreactors. Proc Water Environ Fed., 10, 434-43.

33. Witkowska E. 2006. Preliminary study on the impact of oxygenation upon performance of SBR reactor (in Polish). Inż. Ekolog., 14, 30-40.

34. Yahi H., Madi N., Midoune K. 2014. Contribution to biological treatment of dairy effluent by sequencing batch reactor (SBR). Desalination and Water Treatment, 52(10-12), 2315-2321.
35. Yang Y., Yang J., Zuo J., Li Y., He S., Yang X. Zhang K. 2011. Study on two operating conditions of a fullscale oxidation ditch for optimization of energy consumption and effluent quality by using CFD model. Water Res. 45(11), 3439-52.

36. Zhang X., Zhang F., Zhao Y., Li Z. 2017. Start-Up and Aeration Strategies for a Completely Autotrophic Nitrogen Removal Process in an SBR. Biomed Res Int. 17 art. no. 1089696.

37. Zhang Y., Li C., Xu Y., Tang Q., Zheng Y., Liu H., Fernandez-Rodriguez E. 2019. Study on Propellers Distribution and Flow Field in the Oxidation Ditch Based on Two-Phase CFD Model. Water, 11, 2506.Katsou E., Alvarino T., Malamis S., Suarez S., Frison N., Omil F. and Fatone, F. 2016. Effects of selected pharmaceuticals on nitrogen and phosphorus removal bioprocesses. Chemical Engineering Journal, 295, 509-517. 